\title{
A Study on Vitamin D Levels in Patients Attended at OPD of A Tertiary Care Hospital of Chattogram
}

Shaheda Ahmed ${ }^{1 *}$

Md. Jalal Uddin ${ }^{2}$

A Y M Masud Reza Khan ${ }^{3}$

'Department of Biochemistry

Chattagram International Medical College

Chattogram, Bangladesh.

${ }^{2}$ Department of Community Medicine

Chattogram Maa-O-Shishu Hospital Medical College Chattogram, Bangladesh.

${ }^{3}$ Department of Forensic Medicine Chattagram International Medical College Chattogram, Bangladesh.
*Correspondence to:

\section{Dr. Shaheda Ahmed} Associate Professor

Department of Biochemistry Chattagram International Medical College

Chattogram, Bangladesh.

Mobile : +8801715704218

Email: perveen71@gmail.com

Date of Submission : 26.04 .2019 Date of Acceptance : 28.06 .2019

www.banglajol.info/index.php/CMOSHMC

\begin{abstract}
Background: Vitamin $D$ is a fat soluble vitamin, having important role in calcium and phosphorous metabolism. Many researches support the role of vitamin $D$ against cancer, cardiovascular diseases, fractures and falls, cognitive disorders, Parkinsonism, auto-immune diseases, respiratory ailments and depression. Thus Vitamin D Deficiency (VDD) is an alarming public problem. Purpose of this study was to measure the frequency of hypovitaminosis $D$ among different age and sex group of Chattogram, Bangladesh.
\end{abstract}

Materials and methods: A cross sectional hospital based observational study was conducted over a period of six months from February 2018 to July 2018 at a leading diagnostic complex and hospital of Chattogram. A total of 243 patients were included in the study. Number of male and female respondents were 86 and 157 respectively. Age range was 15-85 years. Blood samples were collected aseptically after an oral informed consent. Serum vitamin D levels were estimated using standard laboratory technique (Chemiluminescent microparticle immunoassay method).

Results: Among 243 respondents, male female ratio was 1:1.83, mean age was $47 \pm$ 16.3 years, prevalence of hypovitaminosis was $82 \%$, among male hypovitaminosis was found in $78 \%$ cases, whereas among female it was a bit higher with $84 \%$. Sex difference was strongly significant with $p$ value of $<0.01$.

Conclusion: The present study has limitation with estimation of only vitamin $D$, in absence of valuable indicators of bone health like serum calcium, bone mineral density and parathyroid hormone. Factors like, less outdoor activities, obesity or covering whole body (Abaiya or burkah) in case of Muslim women, which could be responsible for more hypovitaminosis in case of female was not noticed. But it was very much clear that 45-60 years age group was the most vulnerable with highest level of hypovitaminosis- $D$ in both sexes.

Key words : Hypovitaminosis-D; Metabolism; Chattogram.

\section{INTRODUCTION}

Vitamin D is a fat soluble, steroid containing vitamin, important regulatory factor in calcium and phosphorous metabolism ${ }^{1}$. The vitamin $\mathrm{D}$ level is regulated by different factors like Parathyroid Hormone (PTH) serum calcium level, intestinal absorption and renal function ${ }^{2}$. Vitamin D is naturally synthesized in the skin during exposure to sunlight emitting ultraviolet radiation in the band of 290 to $315 \mathrm{~nm}$. Vitamin D though very little portion also coming from food sources like fatty fish (Tuna, salmon and mackerel) beef liver, cheese, egg yolks and foods fortified with vitamin $\mathrm{D}$, such as some dairy products, orange juice, soya milk. Vitamin D is converted in the liver to 25-hydroxyvitamin $\mathrm{D}^{3}$. The active form of vitamin $\mathrm{D}$ is 1,25 dihydroxyvitamin $\mathrm{D}$, is produced in the kidney ${ }^{4}$. 


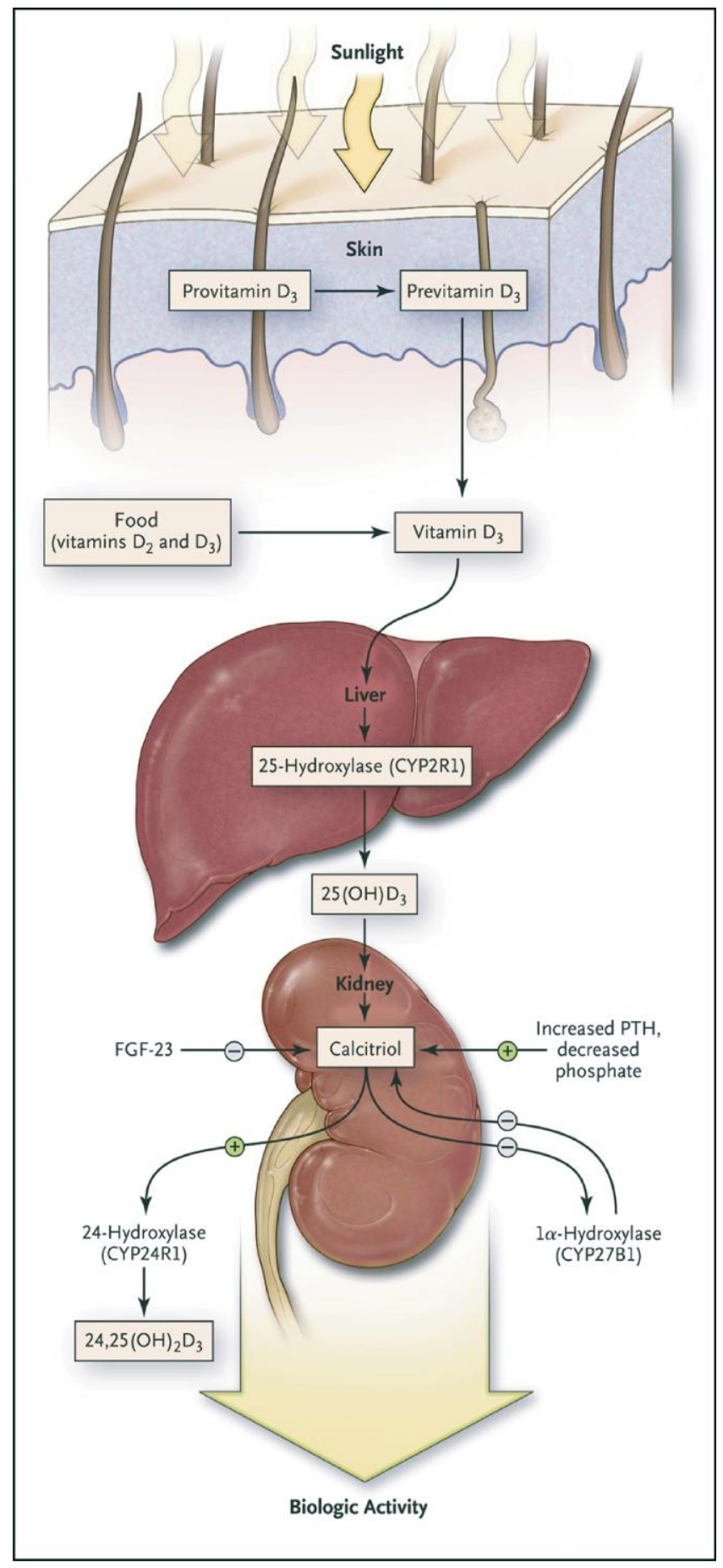

Figure 1 : Vitamin D metabolism

Multiple biological functions like inhibition of cellular proliferation and differentiation, inhibition of angiogenesis, stimulation of insulin production and inhibition of renin production are done by vitamin $\mathrm{D}^{5}$. Its effects on cardiovascular smooth muscles and myometrium are also documented ${ }^{6}$. Many researches support the role of vitamin D against cancer, cardiovascular disease, fractures and falls, cognitive disorders, parkinsonism, auto-immune diseases, respiratory ailments and depression ${ }^{7}$. Thus Vitamin D Deficiency (VDD) is an alarming public health problem.
Different factors affect serum vitamin D level such as, area far from the equator (amount of UVB available from sunlight, during the winter season is insufficient to produce cutaneous vitamin D synthesis), skin pigmentation (Dark skin reduces synthesis), ageing (The more the age the less the vitamin D synthetic capacity) use of sun screen or protective clothing, obesity $\left(\right.$ BMI $\left.>30 \mathrm{~kg} / \mathrm{m}^{2}\right)$, chronic renal, liver and gastrointestinal tract diseases and use of some drugs (e.g. anticonvulsants, glucocorticoids) $)^{8,9}$.

The synthesis of vitamin D (Calcitriol) is stimulated by increased level of Parathyroid Hormone (PTH) and as well as low level of serum phosphate. Low level of serum vitamin D and calcium exerts a positive feedback on PTH, to increase serum calcium level, that stimulates the conversion of $25(\mathrm{OH}) \mathrm{D}$ to vitamin $\mathrm{D}$ in kidney and to increase the absorption of vitamin D from the gut ${ }^{10}$.

Daily recommended dose of Vitamin D is considered between 200-600 IU/day for both male and female from one year to fifty years. The requirement rises to $600 \mathrm{IU} /$ day for people between 51- 70 years, and to $800 \mathrm{IU} /$ day for the people older than 70 years ${ }^{11}$. A recent recommendation from the American Academy of Pediatrics increased the suggested daily intake to $400 \mathrm{IU} /$ day for infants, children and adolescents ${ }^{12}$. Around one billion people have either vitamin D insufficiency or deficiency. Vitamin D deficiency level is, vitamin D level less than 20 $\mathrm{nmol} / \mathrm{L}$, however insufficiency is vitamin D level less than 30 $\mathrm{nmol} / \mathrm{L}(1 \mathrm{nmol} / \mathrm{L}=0.4 \mathrm{ng} / \mathrm{ml})$. Hypervitaminosis of vitamin D may occur when level exceeds $100 \mathrm{nmol} / \mathrm{L}^{13}$.

This study aimed to observe vitamin-D levels in patients attending at OPD of a tertiary care hospital for reasons other than absolute vitamin D deficiency complaints. We also tried to value the impact of age and gender on it.

\section{MATERIALS AND METHODS}

A cross sectional hospital based observational study was conducted over a period of six months from February 2018 to July 2018 at a leading diagnostic complex and hospital of Chattogram to know the vitamin D status of the patients visiting OPD for various medical problems. Total 243 cases were studied. Female were more (157) than their counterpart male (86). Age range of the respondents was 15-85 years. After an informed blood was collected and serum analysed for vitamin D levels.

\section{Inclusion criteria:}

Patients attending at OPD of various specialties with symptoms unrelated to gross vitamin D deficiency were included in the study.

\section{Exclusion criteria:}

Patients with chronic liver and kidney disease, congenital anomalies and malabsorption syndrome were excluded. Unwilling patients were also excluded.

According to Lips classification and Hillock MF et al. the vitamin D status of an individual is defined as: ${ }^{14}$ 
$<20 \mathrm{ng} / \mathrm{ml}=$ Deficient

$20-29 \mathrm{ng} / \mathrm{ml}=$ Insufficient

$30-100 \mathrm{ng} / \mathrm{ml}=$ Sufficient

$>100 \mathrm{ng} / \mathrm{ml}=$ Intoxication

\section{RESULTS}

Total 243 patients were studied for vitamin D levels. Females were more than males by being around $65 \%$. The male female ratio was 1:1.83. The age range was between 15 to 85 years. The mean age was $47 \pm 16.3$ years. Majority of the hypovitaminosis-D respondents in the study were observed in the age group of 46 to 60 years in both sexes, $42 \%$ in case of male and $33 \%$ in case of female. Prevalence of hypovitaminosis D was $82 \%$ in both sex groups with male and female individual percentage were $78 \%$ and $84 \%$ respectively. Sex difference was strongly significant, $\mathrm{p}<0.01$.

Table I : Vitamin D Levels According to Sex $(n=243)$

\begin{tabular}{lcclr} 
Gender & $\begin{array}{l}\text { Sufficient } \\
(\mathbf{3 0 - 1 0 0 ~} \mathbf{n g} / \mathbf{m l})\end{array}$ & $\begin{array}{c}\text { Insufficient } \\
(\mathbf{2 0 - 2 9} \mathbf{n g} / \mathbf{m l})\end{array}$ & $\begin{array}{l}\text { Deficient } \\
(<\mathbf{2 0} \mathbf{~ n g / m l})\end{array}$ & \multicolumn{1}{l}{ Total } \\
Male & $19(22 \%)$ & $40(46 \%)$ & $27(32 \%)$ & $86(35 \%)$ \\
Female & $25(16 \%)$ & $60(38 \%)$ & $72(46 \%)$ & $157(65 \%)$ \\
Total & $44(18 \%)$ & $100(41 \%)$ & $99(41 \%)$ & $243(100 \%)$ \\
\hline
\end{tabular}

Source: Study report 2018

In table $\mathrm{I}$, it is shown that, vitamin $\mathrm{D}$ deficiency is more common in female than that of male with $46 \%$ in female and $32 \%$ in male respectively, whereas insufficiency level shows the opposite picture with dominancy in male group with $46 \%$ and females were a bit less than that group with $38 \%$. Sufficiency level also projected same trend with male majority, $22 \%$ and $16 \%$ respectively. But as a whole female were more sufferer with $65 \%$ than males with $35 \%$.

Table II : Hypovitaminosis-D According To Age Group ( $\mathrm{n}=199)$

\begin{tabular}{lrrr} 
Age Group & \multicolumn{1}{l}{ Male } & \multicolumn{1}{c}{ Female } & \multicolumn{1}{l}{ Total } \\
15-30 years & $07(11 \%)$ & $32(24 \%)$ & $39(20 \%)$ \\
$31-45$ years & $13(19 \%)$ & $28(21 \%)$ & $41(21 \%)$ \\
46-60 years & $28(42 \%)$ & $43(33 \%)$ & $71(36 \%)$ \\
61-70 years & $13(19 \%)$ & $17(13 \%)$ & $30(14 \%)$ \\
$71-85$ years & $06(09 \%)$ & $12(09 \%)$ & $18(09 \%)$ \\
Total & $67(100 \%)$ & $132(100 \%)$ & $199(100 \%)$ \\
\hline
\end{tabular}

Source: Study report 2018

In table II, it is observed that, the most vulnerable age group in both sexes was 46-60 years group, with total hypovitaminosisD level $36 \%$ and male, female percentage were $42 \%$ and $33 \%$ respectively with male dominancy. Whereas, extreme age group, 71-85 years shows least level of hypovitaminosis-D in both sexes, only $09 \%$.

\section{DISCUSSION}

Vitamin D Deficiency (VDD) rate is increasing and these days it is a common problem among many people irrespective of age and sex. In present study, $82 \%$ respondents showed deficiency in vitamin $\mathrm{D}$, which was far more higher than a hospital based report by Rudrajit et al. as $47.5 \%$ and a community based study by Sheik et al. from Pakistan as $57 \%$ cases $^{15,16}$.

Regarding sex variation we found that females were more deficient in vitamin D than males, $84 \%$ and $78 \%$ respectively. Goswami et al found vitamin D deficiency in $80 \%$ female $^{17}$. But opposite figure was observed by Fatima et al as $57.35 \%$ in male and $47.19 \%$ in female ${ }^{18}$. Our study found that only $18 \%$ respondents were sufficient in vitamin $\mathrm{D}$, whereas, reports by Vishal et al. showed $26.83 \%$, both these reports observed were much more better picture than the report of Rachna et al. as $10 \%$ and Rudrajit et al. as $12.5 \%{ }^{19,20,15}$. In present study, hypovitaminosis-D according to age group found that, elderly groups such as 61-70 years and 71-85 years had much less vitamin D deficiency (14\% and $09 \%$ respectively) than the middle age group, $46-60$ years (36\%) It could be due to less number of respondents in the age group of 61-70 years (30 out of 199 hypovitaminosis-D cases) and age group 71-85 years (Only 18 out of 199 hypovitaminosis cases). It could be also due to the fact that elderly group might be having vitamin D and calcium supplements. But opposite figure observed by Fatima et al that with increasing age, the vitamin D levels were gradually declining with lowest levels (Cent percent) noted in the age group $81-90$ and $91-100$ year $^{18}$. Marawah et al from India noted it as $91.2 \%$ in elderly ${ }^{21}$. In our study hypovitaminosis-D in the lowest age group of 15-30 years was seen as $20 \%$ and most commonly affected age group was 45-60 years showed $36 \%$. But Harinaryan CV and Rudrajit et al. showed as $50 \%$ for the age group 21-30 years and $51 \%$ for the age group 51-60 years ${ }^{15}$. Our highest prevalence group for hypovitaminosis-D was 45-60 years age group, whereas Harinaryan CV and Rudrajit et al. reported in the age group of 31-40 years, but Rachana et al. reported highest prevalence of $95 \%$ in the age group of less than $31-40$ years ${ }^{15,20}$. Vitamin D deficiency in elderly most likely due to decreased dietary intake, diminished sunlight exposure, reduced skin thickness, impaired intestinal absorption, impaired hydroxylation of vitamin D in liver and kidney ${ }^{22}$.

Most of the studies reported hypovitaminosis D prevalence in females than in males as $92 \%$ in females by Rachana et al. and $28 \%$ in males, Rudrajit et al. as $53 \%$ in females and $33 \%$ in males ${ }^{20,15}$. Insufficiency is predominant in female, which could be due to diet lack of calcium and vitamin $\mathrm{D}$, covering whole body as dress code for Muslim female, use of sunscreen and indoor life style of female in the subcontinent.

This study was conducted as a hospital based study without other important parameters like PTH, serum calcium levels, and bone mineral density, which are related with vitamin D metabolism. Female respondents were out-numbered than male. Because more females sought medical attention than males. So sample size and sex ratio were not appropriate for concrete findings. Moreover covering the whole body as a religious symbol for Muslim females, percentage of outdoor activities were not noted in the current study. Larger sample size was needed to get a factual picture of vitamin D status. 


\section{CONCLUSION}

Vitamin D deficiency was more in female than in male according to this study, peri and post-menopausal women were more vulnerable group. Regarding this, factors associated with were, limited sun exposure and time spent outdoors, inadequate dietary vitamin D intake (Including supplements), biological consequences of ageing which may lead to increased vitamin D deficiency in the elderly. So, relevant factors should be removed to reduce the hypovitaminosis-D burden.

\section{DISCLOSURE}

All the authors declared no competing interest.

\section{ACKNOWLEDGEMENT}

We are grateful to the patients for cordial cooperation.

\section{REFERENCES}

1. Aleteng Q, Zhao L, Lin H, Xia M, Ma H, Gao J, Pan B, Gao X. Optimal Vitamin D status in a middle-aged and elderly population residing in Shanghai, China. Med Sci Monit. 2017;23:6001-6011

2. Elsammak M.Y, Al-Wossaibi A.A, Al-Howeish A and Alsaeed J. High prevalence of vitamin D deficiency in the sunny eastern region of Saudi Arabia: A hospital-based study. Eastern Mediterranean Health Journal. 2011;7:317-322.

3. Holick MF. Vitamin D deficiency. N Engl J Med. 2007;357:266-281.

4. IOM report on calcium and vitamin D. Washington DC: Institute of Medicine. 2010. (http://www.iom.edu/vitaminD)

5. Stolzenberg-Solomon RZ, Hayes RB, Horst RL et al. Serum vitamin D and risk of pancreatic cancer in the Prostate, Lung, Colorectal and Ovarian Screening Trial. Cancer Res. 2009;69:1439-1447.

6. Khan SM, Mustafa G, Aslam S. Vitamin D deficiency among pregnant women attending a tertiary care hospital. JSZMC. 2014;5:540-543.

7. Nair R, Maseeh A. Vitamin D: The “sunshine” vitamin. J Pharmacol Pharmcother. 2012;3(2):118-126.

8. Webb AR, Kline L, Holick MF. Influence of season and latitude on the cutaneous synthesis of vitamin D3: Exposure to winter sunlight in Boston and Edmonton will not promote vitamin D3 synthesis in human skin. Journal of Clinical Endocrinology and Metabolism. $1988 ; 67: 373-378$

9. MacLaughlin J, Holick MF. Aging decreases the capacity of human skin to produce vitamin D3. Journal of Clinical Investigation. 1985;76:1536-1538

10. Need AG et al. Vitamin D status: Effects on parathyroid hormone and 1,25-dihydroxyvitamin D in postmenopausal women. American Journal of clinical Nutrition. 2000;71:1577-1581

11. Institute of Medicine Committee to Review Dietary Reference Intakes for VitaminD,Calcium. The National Academies Collection:Reports funded by National Institutes of Health. In:Ross AC, Taylor CL,Yaktine AL, Del Valle HB, eds. Dietary reference intakes for Calcium and Vitamin D. Washington DC: National Academies Press (US) National Academy of Sciences. 2011.

12. Wagner CL, Greer FR. Prevention of Rickets and vitamin D deficiency in infants, children and adolescents. Pediatrics. 2008;122:1142-1152.

13. https://ods.od.nih.gov/factsheets/VitaminD-Health Professional/on March18,2017.

14. Holick MF, Binkley NC, Bischoff-Ferrari HA. Endocrine Society Evaluation, treatment and prevention of vitamin D deficiency: An Endocrine Society clinical practice guideline Clin Endocrinol Metab. 2011;96:1911-1930.

15. Rudrajit P, Jayanti R, Ranita. Blood vitamin D levels in a sample population from Eastern India: A pilot study. IJBR. 2014;05[08].

16. Sheik A, saeedZ, Jafri SAD. Vitamin D levels in asymptomatic adults- A population survey in Karachi, Pakistan, PLos One 7 (3):e 33452.doi:10.1371/Journal. Bone .0033452.

17. Goswami R, Vatsa M, Sreenivas V. Skeletal muscle strength in young Asian Indian females after vitamin D and calcium supplementation. A double blind randomized trial. Indian J Endocrinol Metab. 2012;97:4709-4771.

18. Fatima S, Anjum A. A study of 25(OH) vitamin D levels in patients attending a tertiary care hospital of Hyderabad. IJSR 2016;5:45-49.

19. Vishal R, Tandon, Sudha. Prevalence of vitamin deficiency among Indian menopausal women and its correlation with diabetes: A first Indian cross sectional data. Midlife health. 2014;5:121-125.

20. Rachana B, Navyug RS, Jagtesh SS. Prevalence of vitamin D deficiency in North West Punjab population: A cross sectional study. Int. J Appl Basic Med Res. 2015;5:7-11.

21. Marawah RK, Tandon N, Garg MK. Bone health in healthy Indian population aged 50 years and above. Osteoporos Int. 22[11]:2829-2836.

22. Urwashi M, Priyanka S, Shubhra. Current status of vitamin D deficiency in india. Innovations in pharmaceuticals and pharmacotherapy. 2014;2:328-335 